\title{
Continuing medical education for pathologists: an evaluation of the Royal College of Pathologists' Wessex pilot scheme
}

\author{
Clair du Boulay
}

\begin{abstract}
Aim-To discover the attitudes to continuing medical education (CME) of the Wessex pathologists who participated in the Wessex CME pilot scheme and to identify their preferences and difficulties in pursuing $\mathrm{CME}$ activities.

Method-The views of pathologists in the scheme were collected during a period of one year using workshops and discussions. A confidential, anonymous postal questionnaire based on these issues was sent to the 103 pathologists in Wessex who participated in the pilot scheme.

Results-A $64 \%$ response rate was obtained. The respondents identified lack of time and funded study leave as major barriers to CME and highlighted the gap between CME activity and its recognition and funding by employers. They wanted a wide variety of locally based CME activities to be recognised, and they valued local activities that linked theory with practice. They believed that the college scheme tended to favour academic activities over more practical and locally based ones. They found the paired peer review process time consuming but valuable for identifying their learning needs in some cases, but demonstrated that they have mixed preferences about the way they do their CME. Conclusions-The Wessex pathologists believe that $\mathrm{CME}$ is important and have positive attitudes to it. Their attitudes to CME echo the current literature about what makes CME effective. Unless individuals' preferences and difficulties are taken into account, CME programmes in which they participate are not likely to succeed.

(F Clin Pathol 1997;50:1022-1026)
\end{abstract}

Keywords: continuing medical education; attitudes

Continuing medical education (CME) is a process that extends from medical school until retirement. It enables us to enhance our performance and careers, to maintain high standards of patient care, to acquire new expertise, adopt new roles, and manage change. ${ }^{1}$ The education of doctors is now firmly in the public domain. Patients, health commissions, NHS trusts, universities and the General Medical Council all have a stake in promoting effective CME and determining the content of CME activities. ${ }^{2} \mathrm{CME}$ is primarily being coordinated and implemented by the royal colleges and a variety of schemes has been introduced.

\section{Royal College of Pathologists CME programme}

The Royal College of Pathologists decided to replace the existing informal approach of most consultants to CME with a structured system that would ensure that CME takes place on a formal and regular basis. One CME credit equates to one hour of learning time. Members must collect 250 credits over five years. College guidelines outline the categories of educational events and activities that can earn credits. ${ }^{34}$ CME credits can be obtained by a variety of methods. These include: participation in paired peer review; use of distance learning packages; attendance at approved local, regional or national meetings; and academic activities such as publishing books, scientific papers, giving lectures, and editing.

All activities must be approved by the college in advance, and attendance documented. All participants must keep a log book that is ratified by the local college tutor and sent to the college annually. ${ }^{4}$

The Wessex pilot scheme

The Royal College of Pathologists invited Wessex pathologists to pilot two parts of the scheme: paired peer review and the implementation of CME credits.

\section{PAIRED PEER REVIEW}

This is a formative review between equal, mutually respecting professionals who reflect on professional experience and assist each other in identifying their learning needs and career intentions. The objectives of the process are for two career pathologists from the same speciality to meet together to review each other's performance at work. They agree appropriate objectives that will improve the delivery of service and further the individual's career development. ${ }^{13}$ Paired peer review was implemented in Wessex by the production of a video, workshops, discussions, and the production of guidelines for pairing.

\section{CME CREDITS}

All pathologists were sent a log book and referred to the college guidelines. At a series of open meetings and through the Associate Specialist Education Committees, pathologists identified several important issues: 
Table 1 Number of questionnaires sent and returned by specialty

\begin{tabular}{llllr}
\hline & Sent $(n)$ & $\%$ & Returned $(n)$ & $\%$ \\
\hline Histopathology & 48 & 48.5 & 34 & 53.1 \\
Chemical pathology & 10 & 10.1 & 6 & 9.4 \\
Microbiology & 17 & 17.2 & 13 & 20.3 \\
Haematology & 24 & 24.2 & 11 & 17.2
\end{tabular}

- the general implications of re-certification

- practical difficulties of being "signed up" for individual meetings

- the bureaucracy involved in authentication of points

- gaining approval for non-specialty related educational activities

- allocation of points for publications

- the possible unfair advantage to teaching hospital pathologists in relation to peripheral district general hospital pathologists

- the exclusion of local clinicopathological meetings from gaining points.

\section{The basis of this survey}

As a result of the implementation of the Wessex CME scheme, it was apparent that there were important issues and barriers to CME. This survey was based on the views of the participating pathologists and addressed the following questions:

- what are the general attitudes of Wessex pathologists to CME?

- what are their attitudes to the Royal College of Pathologists' CME scheme?

- what are the main barriers to the implementation of the CME scheme in Wessex?

\section{Methods}

A postal questionnaire, based on the issues raised during the pilot year and piloted by 14 consultants, was sent to 103 pathologists in the Wessex region who had participated in the pilot scheme. The questionnaire included factual questions as well as opportunities for free comment. The three main categories of questions related to general issues about $\mathrm{CME}$, paired peer review, and CME points. The attitudinal

Table 2 Responses regarding general issues about CME: preferred learning methods

\begin{tabular}{lcc}
\hline & Number & Valid percentage \\
\hline I find it easy to keep up to date by reading journals \\
Strongly agree & 4 & 6.3 \\
Agree & 12 & 19 \\
Neutral & 20 & 31.7 \\
Disagree & 23 & 36.5 \\
Strongly disagree & 4 & 6.3 \\
Missing & 1 & \\
& & \\
I prefer to keep up to date by going to courses/meetings than reading \\
journals & & \\
Strongly agree & 1 & 1.7 \\
Agree & 17 & 28.3 \\
Neutral & 27 & 45.0 \\
Disagree & 9 & 15.0 \\
Strongly disagree & 6 & 10.0 \\
Missing & 4 & \\
& & \\
I would like to use distance learning packages & \\
Strongly agree & 11 & 18.0 \\
Agree & 22 & 36.1 \\
Neutral & 14 & 23.0 \\
Disagree & 8 & 13.1 \\
Strongly disagree & 6 & 9.8 \\
Missing & 3 & \\
\hline
\end{tabular}

questions included statements requiring a response on a Likert-type rating scale (strongly agree, agree, neutral, disagree, strongly disagree). The questionnaire contained approximately one third attitudinal scale questions, one third free comments, and one third factual questions. The questionnaire was anonymous, the only identifying data on the returns being the consultant's specialty. Complete confidentiality was assured to allow respondents to be open and frank in their replies and comments. An addressed return envelope was included with each questionnaire. The numerical data were analysed using a commercial statistics program (SPSS for Windows version 6.0). The free comments were transcribed verbatim and aggregated into clusters of most frequently occurring comments.

\section{Results}

A total of 103 questionnaires were sent and four were returned unopened. Sixty four replies were received from the remaining 99 questionnaires (a $64 \%$ response rate). Table 1 shows the number of questionnaires sent and returned for each specialty. The percentage of replies in each specialty was comparable to the percentage sent out.

NUMERICAL QUESTIONNAIRE RESULTS

Table 2 shows that only $25 \%$ of respondents found it easy to keep up to date by reading journals. Just over half (54\%) said that they would like to use distance learning packages. Table 3 shows that most respondents $(71 \%)$ were clear that they knew what their learning needs were. For each of the statements relating to having time to go to national meetings, the responses were evenly divided: one third did not have time to go to meetings, one third were neutral, and one third did have time to go to meetings. Respondents were equally divided about how easy it was to obtain funded study leave.

Respondents were equally divided about how easy it was to collect CME credits (table 4). Nearly half (44\%) of the respondents thought that the college guidelines were not clear. Only $16 \%$ thought that collecting CME credits would improve their clinical practice, with $35.5 \%$ strongly disagreeing that this was the case. Eighty five per cent of respondents agreed that the current system of CME credits favoured those in academic departments. There was a strong view that the CME credit scheme should be ratified by individuals on trust $(78 \%)$, and strong disagreement with centralising this process at the college. Fifty two per cent were against the paired peers ratifying each other's CME points. There was an equal mix of views as to whether college tutors or clinical tutors locally should ratify CME points.

The results relating to the paired peer review process showed that $70 \%$ of respondents had met with their paired peer and of these $71 \%$ had met once and $27 \%$ had met twice; one person stated that they had met three times. Of those who had not yet met, $44 \%$ were intending to meet. A total of $59 \%$ of respondents 
Table 3 Responses from the general section on CME issues: potential barriers to CME

\begin{tabular}{|c|c|c|}
\hline & Number & $\begin{array}{l}\text { Valid } \\
\text { percentage }\end{array}$ \\
\hline \multicolumn{3}{|c|}{ I find it difficult to know which areas I need to learn about } \\
\hline Strongly agree & 1 & 1.6 \\
\hline Agree & 8 & 12.7 \\
\hline Neutral & 9 & 14.3 \\
\hline Disagree & 30 & 47.6 \\
\hline Strongly disagree & 15 & 23.8 \\
\hline Missing & 1 & \\
\hline \multicolumn{3}{|c|}{ It is not difficult to obtain funded study leave } \\
\hline Strongly agree & 5 & 7.9 \\
\hline Agree & 16 & 25.4 \\
\hline Neutral & 22 & 34.9 \\
\hline Disagree & 11 & 17.5 \\
\hline Strongly disagree & 9 & 14.3 \\
\hline Missing & 1 & \\
\hline \multicolumn{3}{|c|}{ I am too busy with clinical work to go to national meetings } \\
\hline Strongly agree & 7 & 11.3 \\
\hline Agree & 15 & 24.2 \\
\hline Neutral & 21 & 33.9 \\
\hline Disagree & 13 & 21.0 \\
\hline Strongly disagree & 6 & 9.4 \\
\hline Missing & 2 & \\
\hline \multicolumn{3}{|c|}{ I do not have sufficient time to go to national meetings } \\
\hline Strongly agree & 9 & 14.5 \\
\hline Agree & 16 & 25.8 \\
\hline Neutral & 17 & 27.4 \\
\hline Disagree & 16 & 25.8 \\
\hline Strongly disagree & 4 & 6.5 \\
\hline Missing & 2 & \\
\hline
\end{tabular}

had produced a written learning plan and 12 people had found this useful for identifying their learning needs. However, $66 \%$ were unable to achieve their learning targets for the year. Some $68 \%$ of respondents wanted to see the paired peer review scheme abandoned and only $31 \%$ would be prepared to attend workshops to help them with the process.

ANALYSIS OF FREE COMMENTS.

Free comments appeared on 61 of 64 response sheets. They were transcribed verbatim and

Table 4 Responses relating to questions about CME credits

\begin{tabular}{|c|c|c|}
\hline & Number & $\begin{array}{l}\text { Valid } \\
\text { percentage }\end{array}$ \\
\hline \multicolumn{3}{|c|}{ I find it easy to collect $C M E$ credits } \\
\hline Strongly agree & 4 & 6.5 \\
\hline Agree & 19 & 30.6 \\
\hline Neutral & 19 & 30.6 \\
\hline Disagree & 15 & 24.2 \\
\hline Strongly disagree & 5 & 8.1 \\
\hline Missing & 2 & \\
\hline \multicolumn{3}{|c|}{ The college guidelines on $C M E$ credits are not clear } \\
\hline Strongly agree & 5 & 8.2 \\
\hline Agree & 22 & 36.1 \\
\hline Neutral & 15 & 24.6 \\
\hline Disagree & 17 & 27.9 \\
\hline Strongly disagree & 2 & 3.3 \\
\hline Missing & 3 & \\
\hline \multicolumn{3}{|c|}{ Collecting CME credits will improve my clinical practice } \\
\hline Strongly agree & 0 & 0 \\
\hline Agree & 10 & 16.1 \\
\hline Neutral & 18 & 29.0 \\
\hline Disagree & 12 & 19.4 \\
\hline Strongly disagree & 22 & 35.5 \\
\hline Missing & 2 & \\
\hline \multicolumn{3}{|c|}{ The $C M E$ credit scheme favours those in academic departments } \\
\hline Strongly agree & 19 & 30.6 \\
\hline Agree & 34 & 54.8 \\
\hline Neutral & 6 & 9.7 \\
\hline Disagree & 2 & 3.2 \\
\hline Strongly disagree & 1 & 1.6 \\
\hline Missing & 2 & \\
\hline
\end{tabular}

then clustered into groups of comments. Overall they echoed the opinions given in the rest of the questionnaire.

\section{VALIDITY AND RELIABILITY}

The discussion groups and committee meetings that took place throughout the CME pilot year provided background information on which the content of the questionnaire was based. This helped to ensure face and content validity of the questions. The response rate of $64 \%$ and the even distribution of responses between specialties, suggests that the results are representative of the views of pathologists in Wessex. The internal consistency of the questionnaire itself has been shown by the cross tabulation of responses that show good agreement. ${ }^{5}$ Most (95\%) respondents wrote free comments on their questionnaires and these strongly echoed the answers given on the rating scaled questions. Feedback of the results to the participants through local and national presentations has shown a strong recognition and agreement with the attitudes expressed in the survey.

\section{Discussion}

Studies on the views of participants in CME programmes show that these provide a useful database of opinion about how doctors prefer to do CME. ${ }^{6}$ A questionnaire study of Scottish general practitioners obtained valuable information about the pattern of practice and preferences for doing CME. ${ }^{7}$ Another questionnaire based study ${ }^{8}$ demonstrated the attitudes of general practitioners to re-accreditation, showing a firm preference for the profession to lead the way, with minimal interference and bureaucracy from the government and royal colleges. The results of this survey show that Wessex pathologists recognise the importance of $\mathrm{CME}$ and are actively participating in it.

TIME AND MONEY

Time and money were the most commonly cited barriers for participants in this study failing to meet their paired peer and for going on courses. Doctors need time for study, reflection, and to attend learning courses. Lack of time due to the pressure of clinical work and lack of funded study leave have repeatedly been shown to be major barriers to $\mathrm{CME}$ activities. ${ }^{69}{ }^{10}$ Respondents also highlighted the gap between the funding of CME and NHS trust employers. They repeatedly made the point that if CME is to be accepted as part of employment requirements, then it will be necessary to negotiate for the cost of CME to be linked to NHS Trust business plans. This issue has been discussed in the literature and the funding of CME in the UK remains a source of debate. ${ }^{11}$

VOCATIONAL AND PRACTICE BASED CME

The Wessex pathologists expressed the view that the Royal College of Pathologists should recognise CME activities that are local and based on real practice. The most effective CME in terms of changing doctors' behaviour and practice has been shown to be locally based 
and vocational in nature-that is, relevant and rooted in day to day practice. ${ }^{12}{ }^{13}$ Clinicopathological and case review meetings were considered to be an important part of $\mathrm{CME}$, especially for histopathologists. "They are a powerful stimulus to reading up topics and highly relevant to keeping up to date with day to day practice," stated one respondent. This is a concept supported by the literature and firmly based on the educational principles of adult learning. ${ }^{14}$ Other studies have shown that locally based case reviews, grand rounds, and audit meetings are perceived as valuable and effective ways for doctors to keep up to date in their specialty. ${ }^{1315} 16$

\section{BUREAUCRACY}

The Wessex pathologists expressed the view that the Royal College of Pathologists' scheme is clumsy and bureaucratic. They indicated that they wish to be responsible for their own CME either individually or in small peer groups, with minimal interference from bureaucratic organisations such as the Royal College of Pathologists. The implementation of a top down system of centralised point counting is not well received and options such as accreditation schemes linked with occasional external review or appraisal were all suggested as alternatives This approach is supported in the literature by others.

The organisation and implementation of CME cannot rest solely on the wants of the participants. Medicolegal and re-accreditation issues are becoming increasingly important and are having a major impact on the way that CME is managed. ${ }^{817}{ }^{18}$ Thus there is often a tension between educational wants and needs. Although educational desires are driven by personal choice and experience, there should be a balance between the needs of the individual and those of the organisation. ${ }^{19}$ This tension was expressed in the views of the participants of this study.

\section{FLEXIBLE LEARNING METHODS}

The Wessex pathologists demonstrated a range of preferences for accreditable CME activities. Paired peer review suited some people but not others. "I remain to be convinced about the value of paired peer review, I view it as management fad!" was one comment. In another form it could be expanded into local group meetings where peers share experience and discuss how to help each other meet their learning needs, taking into account the needs of the service. In their free comments, the pathologists suggested that group peer review, external quality assessment schemes, and distance learning would be useful. Other authors have described portfolio learning, reflective learning, problem based learning, and distance learning as effective CME activities. ${ }^{142021}$ It has repeatedly been shown in the literature that flexibility of learning methods is essential for effective CME. ${ }^{122}$

CONTINUING PROFESSIONAL DEVELOPMENT $v$ CME The Wessex pathologists perceived that the Royal College of Pathologists favoured aca- demic (knowledge based) activities over more practical or professional ones. They also recognised the importance of wider ranging professional skills required for keeping up to date, including information technology, management, and interpersonal skills. One respondent commented: "CME is about more than specialist skills. Many consultants fail in their duty through lack of organisation and interpersonal skills." Other activities such as the development of clinical guidelines, audit, and practising evidence based medicine should be included in this broad view. ${ }^{23}$

\section{EFFECTIVE CME}

The characteristics of CME activities that are likely to be acceptable and effective have been described by various authors. ${ }^{124}{ }^{25}$ The key features are that CME should be convenient, accessible, flexible, relevant, tailored to individual needs, provide self assessment and feedback, systematised, and responsive to the corporate needs of the NHS. It is interesting to note that all these points were highlighted by the pathologists who responded to the questionnaire in this survey.

Many doctors are sceptical about the value of CME. Statements such as "this is just formalising what we do anyway" and "where is the evidence that it makes any difference?" are often made and indeed were made in this survey. A recent systematic review of $\mathrm{CME}$ activities $^{13}$ showed that journal reading and attending national meetings were shown to be among the least effective forms of CME. Despite this, the model for many CME credit schemes is based largely on these activities. Credit schemes need to be sufficiently flexible to allow the continuation of traditional CME events alongside less formal but no less valuable professional learning.

\section{CONCLUSIONS}

This study has shown that the attitudes of the Wessex pathologists to $\mathrm{CME}$ are informed and important and echo the current literature about what makes CME effective. Unless individuals' preferences and difficulties are taken into account, CME programmes in which they participate are not likely to succeed.

1 SCOPME Continuing professional development for doctors and dentists. Working paper 1994

2 du Boulay C. Audit of CME for pathologists: strategies and implications. F Clin Pathol 1996;49:100-1.

3 Flynn FV. The Royal College of Pathologists' CME scheme. Postgrad Med f 1996;72(suppl 1):24-5.

4 Flynn FV. CME for career post holders in pathology. Bulletin of the Royal College of Pathologists 1993;82:18-9.

5 Altman DG. Practical statistics for medical research. London: Chapman Hall, 1992.

6 Peaston MJT. Consultant perceptions of CME and teaching

time. Hospital Update 1994;Aug:414-17. Kelly MH, Murray TS. General practitioners' views on continuing medical education. Br f Gen Pract 1994;44:469-71.

Sylvester SHH. General practitioners' attitudes to professional reaccreditation. $B M \mathcal{F}$ 1993;307:912-14

9 Continuing medical education [editorial]. Lancet 1993;342: 1497-8.

10 Kerr DNS, Jones SAM, Easmon CSF. Continuing medical education: experience and opinions of consultants. $B M F$ 1993;306:1398-402.

11 Hangartner R. Continuing medical education in Europe. Postgrad Med f 1996;72(suppl 1):4-5.

12 Mayne K. Practice-linked continuing medical education. Med $\mathcal{F}$ Aus 1994;161:630-2.

13 Davis DA. The science and practice of continuing medical education: a study in dissonance. Ann Intern Med 1993;118:A18-19. 
14 Conn RB. Can continuing medical education prepare the current practitioner for the 21 st century? Arch Pathol Lab current practitioner for

15 Lewkonia RM, Murray FR. Grand rounds: a paradox in medical education. Can Med Assoc f 1995;152:371-6.

6 Slaven AE, Dixon AK, Doyle TC. An audit of clinicoradiologic conferences. Invest Radiol 1994;29:859-63.

17 Troxel DB, Sabella JD. Problem areas in pathology practice: uncovered by a review of malpractice claims. Am f Surg Pathol 1994;18:821-31.

18 Nicol F. Making reaccreditation meaningful. Br $\mathcal{F}$ Gen Pract 1995;45:321-4.

19 Jayawickramarajah PT. How to evaluate educational programmes in the health professions. Medical Teacher grammes in the

20 Engel CE Browne E, Nyarango P, Akor S, Khwaja A, Karim $\mathrm{AA}$, et al. Problem-based learning in distance education: a first exploration in continuing medical education. Med Educ 1992;26:389-401.

21 Al Shehri A, Stanley I, Thomas P. Continuing education for general practice: systematic learning from experience. $\mathrm{Br} F$ Gen Pract 1993;43:249-53.

22 Hayes TM. Continuing medical education: a personal view. BMF 1995;310:994-6.

23 Clayton B. Continuing professional development for doctors and dentists. Postgrad Med $\mathcal{f}$ 1996;72(suppl 1):30-2.

24 Harden RM, Laidlaw JM. Effective continuing education: the CRISIS criteria. Med Educ 1992;26:408-22.

25 Davis DA, Thompson MA, Oxman AD, Haynes B. Changing physician performance: a systematic review of the effect 274:700-5. 